\title{
Los cuentos de hadas, una propuesta para la niñez desde la pedagogía Waldorf
}

Isabel Badilla Zamora

Académica de la División de Educación Básica, Universidad Nacional de Costa Rica (UNA)

isabel.badilla.zamora@una.cr

Recibido: 15 de julio del 2016

Corregido: 18 de abril del 2016

Aceptado: 25 de abril del 2016

"La Antroposofía es un sendero del conocimiento que pretende conducir lo espiritual en el ser humano

a lo espiritual en el universo".

Rudolf Steiner

\section{Resumen}

En este ensayo se ofrece a la persona lectora un acercamiento a los planteamientos básicos de la pedagogía de Waldorf, específicamente en lo pertinente al primer septenio del desarrollo de los niños y las niñas. De igual manera, se plantea una reflexión sobre la importancia de los cuentos de hadas tanto en el hogar como en el jardín de niños.

Se parte de la premisa que para los niños y las niñas entre los 0 a 7 años el desarrollo de la fantasía y de los sentidos, así como el conocimiento del mundo que los rodea, se puede realizar mediante los cuentos de hadas, ya que estos constituyen una herramienta metodológica indispensable dentro del planteamiento de la pedagogía Waldorf.

Este ensayo pretender brindar a los padres de familia, las maestras y los maestros una oportunidad para conocer la pedagogía de Waldorf y valorar la pertinencia de los cuentos de hadas proponiendo sugerencias de cómo utilizar este recurso para promover el desarrollo integral del estudiantado.

Palabras claves: cuentos de hadas, pedagogía Waldorf, primer septenio, imitación metodología, material didáctico.

\section{Abstract}

Fairy tales, an approach for children as proposed by Waldorf pedagogy

In this essay, it is offered to the reader a close up on the basic approaches of the Waldorf pedagogy, specifically the one relevant to the first septennium of children development. It also brings a reflection about the importance of fairy tales in kindergarden.

It is based on its premise on that for children between the ages of 0 to 7 the development of their senses along with fantasy and the world around them can be achieved through fairy tales, since these are a methodological tool essential tool to the Waldorf pedagogy.

This essay hopes to offer an opportunity to bring Waldorf Pedagogy closer to parents and teachers as well as to assess the importance of fairy tales by giving options to bring this resource closer and promote the integrated development of children.

Key words: fairy tales, Waldorf pedagogy, first septennium, imitation, methodology, teaching material. 


\section{INTRODUCCIÓN}

Este ensayo tiene como objetivo presentar un modelo pedagógico que tiene como recurso indispensable la utilización de los cuentos de hadas, para el desarrollo integral de los niños y las niñas en su proceso de formación.

Para poder entender la importancia y el poder de los cuentos de hadas que la pedagogía Waldorf plantea, se hace preciso entender este movimiento desde sus bases. La antroposofía es la ciencia que estudia la "sabiduría de la humanidad", es una manera de ver e interpretar el mundo a partir de una profunda observación del ser humano, que excede su cuerpo físico y penetra en su alma y su espíritu (Steiner 2005). La pedagogía Waldorf forma parte de esta antroposofía , la cual fue creada en 1919 por el filósofo austriaco Rudolf Steiner (1861-1925), quien también ha sido reconocido como padre de la biodinámica, existencialista, científico, estudioso de la espiritualidad y quien a su vez propone una didáctica de formación integral respetando la individualidad, replanteando las bases de la educación memorística o tradicional. Carlgren (2004) explica que la pedagogía Waldorf fundamenta que el ser humano está constituido por cuerpo, alma y espíritu y que esta estructura o composición tripartitita es uno de los principios que caracteriza este modelo pedagógico, y se manifiesta en el querer, sentir y pensar. Rudolf Steiner (2005) reconoce el proceso de aprendizaje y maduración mental de los niños y las niñas, pero considera muy importante conocer y correlacionar los procesos sicológicos con los procesos fisiológicos correspondientes.

Edmunds (1971) señala en su primera conferencia en la secretaría de Educación Pública en México lo siguiente:

Es necesario conocer exactamente cómo se desarrolla nuestro cuerpo a lo largo de la niñez, puesto que nuestro cuerpo es vehículo que sirve para todos nuestros pensamientos, emociones y actuaciones, y si algo falla en este vehículo, tampoco entonces nuestras funciones sicológicas proceden en forma correcta (p. 5).

El ser humano necesita de un balance para que su desarrollo sea integral, cada proceso tiene igualdad de importancia en especial si se considera que para la pedagogía Waldorf el desarrollo de la niñez está estrechamente ligado al desarrollo o etapas evolutivas de la conciencia del ser humano y la humanidad.

Para la antroposofía, el ser humano está formado primeramente por un cuerpo físico, el cual nos identifica con la parte terrenal, este cuerpo está relacionado con el reino mineral. Para fortalecer este cuerpo físico se necesita de agua y una buena alimentación; por un cuerpo etéreo o biofórico el cual está constituido por las fuerzas formativas que dan vitalidad al cuerpo físico y que nos permiten el debido funcionamiento de nuestro organismo, este cuerpo etéreo está relacionado con el reino vegetal, es el que estimula las sustancias y las fuerzas del cuerpo físico para que se sintonicen y den paso a diversos procesos tales como el de crecimiento, siendo este la esencia del mismo. Se necesita tener buenos hábitos y ritmo para fortalecer el cuerpo etéreo. Para Steiner (2005) "el cuerpo etéreo corresponde a una estructura energética; son fuerzas activas, no es materia, y el cuerpo astral o sensible es una estructura integrada por imágenes dotadas de movimiento interior, luz y color" (p. 8). El ser humano también está conformado por un cuerpo astral o sensible contiene anhelos, pasiones, dolor, emociones e instintos, todo lo que carecen el resto de las criaturas que solo tienen cuerpo físico y etéreo, está relacionado con el reino animal. El cuerpo astral está formado por el alma consciente, alma racional y el alma sensible, este cuerpo astral se fortalece a través de la meditación y su esencia es el movimiento.

Y finalmente, el Yo, quien es el portador del germen del espíritu, es la expresión del alma superior y su función es según Steiner ennoblecer, depurar el resto de los cuerpos y perfeccionarlos. 
Otra característica o principio de la pedagogía Waldorf es la división del desarrollo evolutivo del ser humano en septenios. Para Steiner (2005) los principales septenios son los siguientes:

De los 0 a los 7 años, se debe destacar lo bueno, durante este periodo el niño y la niña preescolar aprenden mediante la imitación y esta va más allá del hablar y observar el medio ambiente que lo rodea. Durante este tiempo, la fuerza anímica que predomina en el infante es la voluntad y la culminación de esta etapa se ve marcada con el cambio de dentición. En este septenio es cuando el cuerpo físico tiene un mayor desarrollo visible.

De los 7 a los 14 años la población infantil vive intensamente su individualidad como resultado del desarrollo anímico del sentimiento. En este segundo septenio se cultiva lo bello y esta belleza se desarrolla a través de la imaginación por medio de las artes. Los niños y niñas atraviesan lo que en la pedagogía Waldorf se conoce como "Rubicón" o también llamado el punto de no retorno a la infancia, se sienten desprotegidos, solos, abandonados y se vuelven muy críticos con aquellas personas que más los aman. Hay un cambio de conciencia ya que empiezan a cuestionar todo lo que antes daban por un hecho. En esta etapa hay una imagen diferente de su propio cuerpo, aparecen temores y un nuevo tipo de aburrimiento, ya no juegan como antes y compartir con iguales pasa a ser parte importante en su vida.

Finalmente de los 14 a los 21 años, se evidencia una maduración de la personalidad, en este septenio presentar y mostrar lo verdadero y justo es fundamental porque predomina el pensamiento. En esta etapa en las escuelas que siguen los lineamientos de la pedagogía Waldorf se trabaja mucho con sistemas lógicos, investigaciones y prácticas científicas.

Para efectos de este ensayo, se busca profundizar un poco más en los infantes durante el primer septenio. Para Steiner (2005) los tres primeros años son los más importantes en el desarrollo del ser humano. Todo el cuerpo del infante es, en esos años, un órgano sensorio inicia con la boca, en la cual se encuentra localizado el sabor y en el acto de alimentarse se ven involucrados hasta las extremidades. Esta sensación se va extendiendo hacia los ojos y a los oídos cuando capta el mundo que lo rodea, cuando el infante logra captar su alrededor es el momento en que reconoce su cuerpo y aprenden de este a través de la acción.

Las tres facultades que según Steiner, condicionan la vida entera del ser humano y nos diferencia de los animales, son las siguientes: el andar, el hablar y el pensar.

Al empezar a andar, según Steiner (2005) "conquista su justo equilibrio en el mundo espacial" (p. 13). El andar va más allá de utilizar las piernas y los pies, ya que involucra todo el aparato motor. Esta facultad de andar implica que gradualmente podrá fijar la mirada, fortalecer los músculos del cuello y cabeza, orientarse, adecuar los brazos y piernas, darse vuelta, sentarse y erguirse al espacio que lo rodea. La realización de todas estas actividades requiere de un gran trabajo de voluntad. Con sus primeros pasos el infante conquista el espacio y confronta la gravedad. Esto ocurre durante el primer año de vida.

\section{LA NIÑEZ DE LOS O A LOS 7 AÑOS}

El hablar según Steiner (2005), es la culminación de erguirse ante el mundo "todo matiz del habla deriva de la organización del movimiento; todo en la vida comienza con gestos, y el gesto se transforma interiormente en lenguaje" (p. 14). Los infantes empiezan imitando sonidos; eventualmente, si es expuesto a escuchar a los adultos a su alrededor irá integrando palabras, poco a poco irá dándole sentido a lo que escucha y al lenguaje que va adquiriendo, con el hablar el niño y la niña entran en contacto con la vida espiritual humana. Sin lenguaje no se puede expresar el pensamiento, aunque el mismo esté presente, una persona podrá definir y procesar lo que experimenta dependiendo del vocabulario que haya adquirido. El lenguaje se empieza a adquirir generalmente, en el segundo año de vida. 
Y finalmente, el pensar es el resultado del movimiento, del andar y del hablar. El pensar viene de la capacidad de individualizarse, separarse de la madre y del medio que lo rodea. El desarrollo de la memoria, así como el jugar son fundamentales para poder pensar. Cuando un niño o una niña empieza a pensar, se da el primer impulso del "Yo", esto ocurre aproximadamente a los 3 años.

Mediante el ritmo, la rutina, la voluntad, la imitación, la repetición y el orden; el niño y la niña obtienen las herramientas necesarias para desarrollar las destrezas que necesita para regularse a nivel físico, emocional y sentirse en armonía. La persona docente debe ser un buen ejemplo para sus estudiantes, puesto que sus gestos y hasta su estado anímico influencian a los niños y las niñas. Durante este periodo se guían por su voluntad, primero hace, luego siente y por último piensa, mientras que la persona adulta primero piensa, luego hace y por último siente. La repetición de actividades le permite al niño y a la niña adueñarse de ellas, incorporarlas, transformarlas y recrearlas, con la repetición se trabaja la memoria y se ejercita la voluntad.

El ambiente en el que el infante se desarrolle debe de tener un ritmo. Para la pedagogía Waldorf el ritmo es sinónimo de inhalación y exhalación, significa contracción y expansión, movimiento y descanso, es orden, es repetición y todo esto le ofrece seguridad. Y esta palabra encierra más de lo que comúnmente interpretaríamos como un horario. Villasana (Comunicación personal 22 de julio, 2010), comenta con respecto al ritmo que el niño puede "... predecir y a su vez aprender a auto- regularse, la tarea fundamental del niño es convivir, aprender a vivir con otros". En las escuelas Waldorf existe un ritmo diario, semanal, mensual y anual.

La respiración le provee equilibrio al niño. A nivel físico la respiración se trabaja por medio del juego libre, del ritmo del día. Se exhala cuando las actividades son más libres, se inhala cuando se realiza un trabajo más tranquilo y guiado. A nivel etérico (energético) la respiración se siente en el trabajo que realizan los docentes, el cual va a ser imitado por sus estudiantes. Y a nivel astral la respiración es palpable en la manera en que nos relacionamos con la niñez y los colegas.

Steiner (2005) expresa que a través del juego libre el niño y la niña incorporan el mundo que los rodea, ya que es ahí donde desarrollan su propia fantasía, con la experimentación del espacio y representación todo lo que para ellos es significativo, en el juego los niños y niñas encuentran soluciones a situaciones específicas; por ejemplo, a formar torres con cubos de madera sin que se caigan, sin intervención del adulto.

El juego libre, así como las actividades que se desarrollan durante la semana en el jardín de niños; por ejemplo, coser, hacer pan y limpiar, son el vehículo por el cual los niños y las niñas imitan su entorno y con estas prácticas aprenden. Según Knischnick (s.f.) el juego es "fenómeno primordial de toda evolución infantil" (p. 337). Por otra parte Bühler y Brotberck (2011) comentan que el significado de estos juegos antroposóficamente hablando da "calor y vivifica el organismo entero" (p. 46).

Los niños y las niñas imitan para aprender a ser y de alguna manera para integrarse en el mundo que los rodea, esta actividad la realizan mientras juegan. Por lo que para la pedagogía Waldorf se debe proteger el estado de fantasía y ensoñación en el que viven los niños y las niñas, ya que de esta manera se protege su inocencia. Knügelgen (s.f.) señala que se debe ofrecer un medio ambiente armónico, bello y puro que esté desligado del mundo agitado y en ocasiones engañoso en el que vivimos.

Por esta razón los juguetes utilizados en los jardines Waldorf son "no terminados", son sencillos, naturales, sin formas definidas o preestablecidas; por ejemplo, en el salón se encuentran canastas con tucos de madera, con telas, conchas, piedras, ramas, semillas y arena; estos son en otras palabras, materiales que estimulan el desarrollo de la imaginación. Naranjo (s.f.) define el material que deben utilizar los niños como aquel que sienta "las bases del pensamiento" (p. 3). Ya que en la pedagogía Waldorf, los materiales están dirigidos a conocer el medio que rodea al infante y a experimentar. Las vivencias adquiridas durante el juego crean conceptos que son las bases para el desarrollo intelectual. Estos juguetes no están 
elaborados o seleccionados para entretener a los niños y a las niñas como los hacen los juguetes actuales. La función de los mismos, es justamente provocar las reacciones de los niños y las niñas, generar acciones innovadoras y creativas que permitan mediante su uso expresar las emociones, sentimientos y razonamientos de los infantes.

\section{CUENTOS DE HADAS}

Ahora bien, entre todas estas actividades que pertenecen al ritmo de la clase diaria y semanal se encuentran los cuentos de hadas que son la base de la enseñanza a nivel preescolar, ya que su importancia radica en fomentar la fantasía. Como género literario el cuento es una narración breve, ficticia donde participa un número limitado de personajes, con un argumento sencillo y puede ser transmitido de forma oral o escrita. Las historias que contienen estos cuentos tienen origen en el principio de los tiempos y son las que llevan el alma del niño a descubrir los tesoros de las diferentes etapas del desarrollo de la humanidad. Por su importancia, este tipo de literatura ha sido transmitida de generación en generación, en algunos momentos modificados, pero en esencia mantienen lo que Knügelgen (s.f.) señala como "... los secretos de la existencia. Los orígenes suprasensibles del hombre, sus pruebas, sus victorias..." (párr. 2). Para Vladimir Propp citado por Rubio (2007), el origen de los cuentos de hadas se enmarca en ritos de las antiguas civilizaciones y que estos relatos en su momento fueron secretos y sagrados.

Según Dan Udo de Ades (2010) citado por Urrego (2012) para la pedagogía Waldorf,

Los cuentos de hadas son concebidos como una descripción objetiva que reflejan la realidad espiritual vital de ser humano, ya que, dan sentido de pertenencia, de identidad, nos guían en un determinado proceso de desarrollo, nos dicen cuáles son los valores de nuestra sociedad, los roles adscritos a cada género, cuál es nuestro origen y cuál debería ser nuestra meta (p.11).

Muchas veces los cuentos de hadas han sido comparados con los refranes ya que poseen un lenguaje similar, ambos expresan una verdad que se relaciona con el hombre, sin embargo, el cuento de hadas expresa estas verdades a través de imágenes las cuales son el lenguaje del alma. Velásquez (2010) comenta que las imágenes que contienen los cuentos de hadas "representan la explicación de los antiguos moradores de la tierra ante lo que acontecía con el ser humano y la naturaleza" (párr. 3). Cuando un niño o una niña escucha estas narraciones, las imágenes que salen de ellas, quedan impregnadas en su alma. Las imágenes de los cuentos de hadas provienen del mundo espiritual y contestan muchas interrogantes que inconscientemente los niños y las niñas tienen a cerca del mundo. O’Neal (2005) expresa que los cuentos de hadas "le hablan al niño en su propio idioma imaginativo... le guiaban hacia el amor a la verdad, a lo bello y a lo bueno." (p. 318). Los cuentos de hadas llevan a los niños y a las niñas a encontrar soluciones, y ponen las bases para que tengan una actitud valerosa y confiada ante la vida.

En la pedagogía Waldorf se sugiere los cuentos de los hermanos Grimm que contienen los antiguos misterios del mundo. Zapién (comunicación personal 18 de julio, 2011); comenta que "los cuentos nacieron entre aquellos que escuchaban con atención a los seres aptos para hablarles de ellos... podemos decir que en esos viejos cuentos, vive el espíritu de toda la humanidad" pero lamentablemente, ya no se leen cuentos como antes, ya que están sujetos a la interpretación que hace el adulto de ellas. El adulto reprime u omite algunas escenas, ya que le resultan crueles o inapropiadas y hasta repulsivas; sin embargo, el niño o la niña hacen una interpretación distinta de cada historia, las imágenes las crean los infantes durante la narración de los cuentos, dependiendo del sentido y la necesidad de cada uno, estas se transforman en acciones en el futuro. Las imágenes pueden dar esperanza cuando la tragedia acompaña al personaje principal y lo hace diestro para resolver vicisitudes y crear oportunidades de crecimiento con el logro de objetivos propuestos, siendo justos y bondadosos en el proceso. Y es así, como los pequeños 
aprenden sobre la vida misma y el mundo que los rodea. El mal puede estar representado por un gigante, una bruja o el lobo, estos personajes malvados al final de las historias reciben su merecido y el bien siempre sale triunfante, este final feliz deja a los niños y las niñas llenos de confianza en el porvenir.

En el jardín de niños que sigue una filosofía Waldorf un cuento se trabaja hasta por tres semanas, dando la oportunidad a los infantes de guardar e impregnarse de estas imágenes.

Para ejemplificar las imágenes que traen los cuentos de hadas, se explicarán algunas de las imágenes arquetípicas, concepto creado por Carl Gustav Jung y definido como formas ancestrales e innatas de percepción que determinan la manera de captar el mundo y que se manifiestan en el inconsciente; la fuente misma de nuestro ser que tiene el cuento Los ducados caídos del cielo de los hermanos Grimm:

Este cuento carece de paisajes y animales, el cuento narra la historia de una niña que pierde todo y no sabe qué hacer.

- La niña representa el alma humana.

- Lo único que le queda es su ropita, lo que significa que esa alma aún conserva el deseo de pensar, sentir, hacer y desear.

- La niña se encuentra a un mendigo que le dice que le dé algo de comer, la niña le regala lo único que tiene un pedazo de pan. Este pan suple las necesidades del cuerpo físico. La niña, que representa el alma ya no necesita alimentar a su cuerpo físico por lo que regala el pan que representa el deseo de alimentar ese cuerpo.

- La niña encuentra a un niño que llora de frío y que le pide algo con que cubrir su cabeza, la niña le da su gorro; el gorro representa el deseo de pensar y en este camino por el que el alma transita ya no necesita de pensar.

- Ahora al paso de la niña sale un niño, el cual no lleva corpiño y la niña se lo da. La niña ya no tienen deseos, ni pensamientos. Aquí se despoja de su corpiño que cubre su torso, donde se alojan los sentimientos.

- Aparece otra niña y le pide su faldita. La cual cubre el vientre donde se desarrolla la vida. La niña renuncia al deseo de hacer vida.

- El campo que recorre la niña es el camino que ella quiere seguir para encontrar la luz, pero al verse despojada de todo lo que tenía se queda sola en el bosque oscuro. Y con todo lo que ha dado llega a purificarse y a concentrar su propia luz.

- Y al final a la niña le caen ducados de oro del cielo. El oro es representa pureza y eso lo recibe la niña al haber transitado un camino de despojarse del deseo de sentir, pensar, hacer y desear hacia la vida eterna.

Los cuentos de hadas pueden inspirar a los niños y las niñas a realizar actividades artísticas ya que tienen gran poder por toda la sabiduría que poseen. Además para fomentar la imaginación, entendida esta como un estado sano del pensar y sentir, se necesita de escuchar imágenes, es entonces la audición el camino más directo para vivenciar el cuento y no la visión, de esta manera las imágenes arquetípicas cobran vida con mayor facilidad en el alma y la imaginación del niño. No hay necesidad de tener ilustraciones con interpretaciones ya preconcebidas.

Ahora bien, ¿quién puede leer los cuentos de hadas a los niños y las niñas? Todos pueden, sin embargo, la actitud que se debe de tener es diferente a la que se tiene cuando se desea leer un cuento a estudiantes con el objetivo superficial de enseñarles vocabulario o mantenerlos quietos. El narrador debe acceder conscientemente a los cuentos y creer en la realidad de los mismos, debe hacer el cuento suyo, 
debe sumergirse en su atmosfera para que así estos puedan transmitir la sabiduría que contienen y para que los niños y niñas puedan captar las imágenes que de estos se desprenden.

¿Cómo deben contarse los cuentos de hadas?

Los cuentos de hadas deben leerse de manera sencilla, sin adornos para no debilitar las imágenes que de ellos se desprende. Deben ser narrados con soltura y naturalidad. Chubarosvsky (2014) dice que la función de narrar un cuento sin dramatizaciones es "transmitir esas imágenes con la mayor neutralidad y sencillez posible, para que el niño pueda, con libertad escoger de ellas el alimento anímico que necesita" (p. 120).

Se invita al narrador a conocer los cuentos de memoria; nunca cambiar las palabras, a pesar de que el niño no comprenda alguna de ellas, son estas las que se convierten según Haes (2011) en "misterios sonoros" (p. 158) y es exactamente ahí donde radica lo oculto y esencial del cuento y donde la comunicación empieza a darse en el alma del infante donde ambos, lector como audiencia, estén relajados disfrutando del regalo que el cuento les brinda.

Esta es una lista de cuentos que han sido sugeridos y recopilados por Tamara Chubarovsky (2014) en su libro Cuentos para Ver, Oír y Sentir para ser contados a niños y niñas a partir de los dos y medio años, estos son cuentos populares que provienen de varios países y que poseen mucha repetición:

- El nombre del árbol

- Juanito pepita de manzana

- El hombrecillo de otoño

- La ovejita blanquita casa casita

- La liebre y la zanahoria

- La gallinita

- El gusanito

- La niña que quería ser llevada por doquier

- Las cabras y la abeja

- Los tres cabritillos

- El patito ensaya su voz

Los siguientes cuentos son para niños y niñas que están entre los tres y siete años, estos cuentos pertenecen a la colección de los hermanos Grimm, las cuales empezaron a ser publicadas desde 1812 y han sido traducidos en más de 170 idiomas:

- El Rey - Rana

- El lobo y las sietes cabritas

- Gentuza

- Los enanitos del bosque

- El sastrecillo valiente

- Los músicos de Brema

- El Piojito y la Pulguita

- Verdezuela

- Los duendecillos. Cuento primero

- Juanito y Margarita

- La reina de las abejas

- La oca de oro

- La Cenicienta

- Madre Nieve

- Los siete cuervos

- Caperucita roja 
- Gachas dulces

- La bella durmiente del bosque

- Los fámulos

- Blanca nieves

- Los ducados caídos del cielo

- La hija del molinero

- Blanca nieves y Rojaflor

Al contar cuentos de hadas el ritmo del corazón se sintoniza y en el resplandor del niño y la niña se ve la paz y serenidad que muchas veces necesitan antes de dormir.

Para ello la metodología que la pedagogía Waldorf sugiere es la siguiente:

1. Elegir libros sin imágenes para así dejar volar la imaginación de los pequeños.

2. Mantener un tono de voz natural sin exagerar o cambiarla.

3. Narrar las historias en la medida de lo posible.

4. Contar solo un cuento a la vez y si es posible varias veces en diferentes días. Estos le ayudará al niño o niña a crear mejor la imagen y a desarrollar su imaginación.

5. No se deben leer historias donde no se tome en serio la figura del ser humano.

6. Disfrutar el cuento para que este sea de provecho para todos.

\section{CONCLUSIONES}

Este ensayo plantea lo que pueden llegar a hacer los cuentos en el "Yo" del niño o niña. Las imágenes que de ellos se desprenden se convertirán con el transcurso del tiempo en herramientas para poder enfrentar diversas situaciones que la vida nos presenta.

- $\quad$ El niño interpreta los cuentos de una manera menos intelectualizada que el adulto.

- Los cuentos de hadas transmiten y fortalecen valores que se ven agredidos en la actualidad.

- Los cuentos de hadas pueden convertirse en una herramienta pedagógica útil en el salón de clase, un recurso didáctico, que forme parte de una estrategia para el trabajo cotidiano

- La hora del cuento crea un lazo especial entre el docente y estudiantes, de manera tal que el compartir sentimientos y vivencias enriquecen el proceso de enseñanza aprendizaje.

- Desde el punto de vista social se desarrolla la habilidad de expresar sentimientos y diferencias de criterio, esto sin dejar de lado el refuerzo que se da a valores tales como el respeto y la tolerancia a gustos y diferentes puntos de vista.

- El narrar o leer cuentos le permite de manera indirecta al docente o padre de familia enseñar vocabulario, reforzar estructuras gramaticales, mostrar a sus alumnos o hijos la correcta pronunciación y la entonación cuando se realizan lecturas en voz alta.

- Los cuentos estimulan el hábito de la lectura, la imaginación y ayudan a desarrollar la memoria, por lo que su uso ha sido por tradición, una excelente estrategia pedagógica.

- Las actividades que pueden desplegarse de leer un cuento son infinitas, estas pueden enriquecer el desarrollo del estilo de aprendizaje dominante en el niño, ya sea a través de dibujos o representando 
a los personajes en dramatizaciones y pueden guiar el desarrollo del currículo en cualquier asignatura. En especial si los contenidos que se deben cubrir son abstractos. Por ejemplo, con el cuento de Rapunzel se puede estimar el crecimiento del cabello de la hermosa niña y la longitud que podría tener el mismo, al cabo de 5 años. La lechuga prodigiosa puede constituirse en un recurso para estudiar los diferentes grupos alimenticios o las etapas del crecimiento de las plantas, todo esto se puede lograr permitiendo el desarrollo de la imaginación y promover que el aprendizaje sea significativo.

- Para la pedagogía Waldorf los cuentos de hadas son una estrategia indispensable, ya que fortalecen la voluntad del niño y la niña a través de la repetición constante, además transmiten realidades o verdades por medio de imágenes que son dignas de ser imitadas o reproducidas por su valor arquetípico. Para el docente o padre de familia narrar cuentos es sinónimo de dedicación y voluntad ya que deben memorizarlos, mantener la magia que en ellos se encierra por tres semanas.

- El contar cuentos es un trabajo que requiere disciplina por sus características y un ritmo establecido ya sea en el hogar como en el salón de clase. Se debe de leer cuentos con seriedad y con la convicción de que en ellos los niños y niñas se impregnarán de valor, justicia y bondad.

- Este ensayo expone algunas alternativas de cómo trabajar con el recurso de los cuentos de hadas, sin importar el campo de acción, ya que se educa y se forma en todo momento.

- Las sugerencias que se brindan en este ensayo sean de ayuda para quienes participan en los procesos formativos y de aprendizaje de niños y niñas; padres y madres de familia, así como docentes que están o no ligados directamente con la pedagogía Waldorf, y que deseen compartir el mundo misterioso de los cuentos de hadas, la sabiduría que ellos encierran, aunque el espacio laboral no se preste para que se puedan desarrollar estas actividades. No se pueden usar excusas para privar a los niños y las niñas de semejante riqueza.

- Los cuentos de hadas deben ser una estrategia para trabajar con la niñez y aprovechar todo el mundo de ilusión, creatividad y fantasía que les caracteriza y de una manera lúdica que aborde también, contenidos programáticos que muchas veces podrían resultar áridos para la niñez, pero que mediante recursos didácticos como el señalado y enmarcados en la filosofía Waldorf, pueden ser un apoyo para la labor formativa de docentes, padres y madres de familia.

\section{REFERENCIAS}

Bühler, W. y Brotbeck, K. (2011). La Educación de la Voluntad. Buenos Aires: Antroposófica.

Carlgren, F. (2004). Pedagogía Waldorf Una Educación hacia la Libertad. Madrid: Rudolf Steiner.

Chubarovsky, T. (2014). Cuentos para Ver, Oír y Sentir, España: Imprenta Gráficas Romero.

Edmunds, F. (febrero, 1971). El Problema del Hombre en Nuestra Época Tecnológica. En Steiner, R. El Primer Septenio la Educación Preescolar según Rudolf Steiner. (3-12). Buenos Aires: Antroposófica.

Haes, U. (2011). El niño y los Cuentos que nos dicen sus imágenes. Buenos Aires: Antroposófica.

Knügelgen, H. (2005) Edad de la Imitación en Steiner, R. (2005). En Steiner, R. El Primer Septenio la Educación Preescolar según Rudolf Steiner. (126-132). Buenos Aires: Antroposófica.

Naranjo, S. (s. f.). Pedagogía Waldorf. Scribd digital documents library. Recuperado de http://es.scribd. com/doc/48748253/Los-Septenios-en-la-Educacion-Waldorf

O’Neal, G. (2006). Los usos del encantamiento. En Steiner, R. (2005). En Steiner, R. El Primer Septenio la Educación Preescolar según Rudolf Steiner. (317- 322). Buenos Aires: Antroposófica. 
Rubio, C. (2007). Los Cuentos Viejos o Diálogos con el Universo. Revista Electrónica Educare, 11(2), 89-102. Recuperado de http://www.revistas.una.ac.cr/index.php/EDUCARE/issue/view/194

Steiner, R. (2005). Andar, hablar y pensar. En Steiner, R. El Primer Septenio la Educación Preescolar según Rudolf Steiner. (13-26). Buenos Aires: Antroposófica.

Urrego, A. (2012). Los cuentos de hadas en la pedagogía Waldorf una reflexión pedagógica. Recuperado de http://bibliotecadigital.usbcali.edu.co/jspui/bitstream/10819/1070/1/ Cuentos_Hadas_Pedagogia_Urrego_2012.pdf

Velásquez, S. (2010). El niño pequeño y los cuentos de hadas. Al Alba. Número 4(1), octubre, 4-5. 